Brazilian Journal

of Chemical

\title{
SYNTHESIS AND CHARACTERIZATION OF Al- AND Ti-MCM-41 MATERIALS: APPLICATION TO OXIDATION OF ANTHRACENE
}

\author{
R. S. Araújo ${ }^{1 \dagger}$, F. S. Costa $^{2}$, D. A. S. Maia ${ }^{2}$, H. B. Sant ${ }^{`}$ nna $^{2}$ and C. L. Cavalcante Jr. ${ }^{2 *}$ \\ ${ }^{1}$ Programa de Pós-Graduação em Química Inorgânica, Universidade Federal do Ceará, \\ Campus do Pici, B1. 940, Fortaleza, CE - CEP 60455-760, Brazil. \\ †Current Address: CEFETCE, Centro Federal de Educação Tecnológica do Ceará, \\ Av. 13 de Maio 2081, CEP: 60040-531, Fortaleza - CE, Brazil. \\ ${ }^{2}$ Grupo de Pesquisas em Separações por Adsorção (GPSA), Departamento de Engenharia Química, \\ Phone: +(55) (85) 3366-9611, Fax: +(55) (85) 3366-9601, Universidade Federal do Ceará, \\ Campus do Pici, Bl. 709, CEP: 60455-760, Fortaleza - CE, Brazil, \\ E-mail: celio@gpsa.ufc.br
}

(Received: March 28, 2005 ; Accepted: December 20, 2006

\begin{abstract}
The synthesis and characterization of new molecular sieves of the MCM-41 type are presented in this study. Samples were obtained from the alkoxides of $\mathrm{Si}, \mathrm{Ti}$ and $\mathrm{Al}$ and different long-chain amine and alkylammonium salts surfactants, by the sol-gel method, through moderate agitation at room temperature. The reactions were conducted in two steps, acid hydrolysis $(\mathrm{pH}=2)$ and alkaline condensation $(\mathrm{pH}=10)$, both taking about 90min. The synthesized crystals were characterized using infrared spectroscopy, thermogravimetry and X-Ray diffraction. Pore diameters and surface areas were measured by $\mathrm{N}_{2}$ adsorption at $77 \mathrm{~K}$. Catalytic tests were conducted for anthracene oxidation using different oxidants $\left(\mathrm{H}_{2} \mathrm{O}_{2}\right.$, alkylhydroperoxide) and organic solvents (benzene, tetrahydrofuran).

Keywords: Synthesis; Characterization; MCM-4; Anthracene oxidation.
\end{abstract}

\section{INTRODUCTION}

Porous solids are widely used in industrial applications related to the preparation of adsorbents, catalysts and ion-exchangers as well as for future use in advanced technologies involving semiconductors, photoreceptors, and enzymatic complexes (Sayari, 1996). Zeotypical structures with pore diameters ranging from 2 to $12 \AA$ have traditionally been used in catalytic processes. These materials are subdivided into three main categories: zeolites (e.g., A, X, Y), aluminum phosphates (AIPO's) and metalophosphates with large pores (VPI-5, JDF-20, etc). Several industrial processes use microporous zeolites with pore diameters ranging from 0.5 to $0.6 \mathrm{~nm}$ in the separation and catalysis phases (e.g. catalytic cracking, xylenes separation and isomerization)
(Reddy and Song, 1996; Selvam et al., 2000; Corma et al., 1994). This structural characteristic is a limiting factor for the processing of higher molecular weight hydrocarbons (Biz and Occelli, 1998). In 1992 a significant change took place in nanoporous science when Mobil researchers reported an aluminosilicate synthesis with uniform size in the mesoporous materials range (2 to 50nm) (Beck et al., 1992; Kresge et al., 1992). These materials, named M41S, have structural characteristics directly related to the conditions of the synthesis: nature of the surfactant, $\mathrm{pH}$, presence of electrolytes, temperature, solvents, and time of reaction (Cassiers et al., 2000; Ryoo and Kim, 1995; Arnold et al., 1999).

The main difference in the preparation of zeolites and of M41S-type materials consists in the action of directing surfactant agents (templates), which

*To whom correspondence should be addressed 
organize themselves in water solution forming either specific compositions or liquid crystals (Sayari, 1996). According to this mechanism, the Mobil scientists found three different forms: a hexagonal phase, a hexagonal arrays of molecules (MCM-41 family); a cubic phase (MCM-48 family); and an unstable lamellar phase (MCM-50 family). Various synthesis strategies are used in the preparation of the mesostructured materials, especially the following: the hydrothermal method (typically described as the treatment of a silicate solution between 80 and $140^{\circ} \mathrm{C}$ for two or more days) and the sol-gel method (related to the hydrolysis and condensation of metallic alkoxides at specific $\mathrm{pHs}$ ).

There has recently been an increased interest in the insertion of metals with high redox potentials $(\mathrm{V}$, $\mathrm{Cr}, \mathrm{Ti}, \mathrm{Fe}, \mathrm{Ni}$, etc) into the original structure of the MCM-41 type (Ulagappan and Rao, 1996; Rodriguez-Castellón et al., 2003; Tuel, 1999; Blasco et al., 1995). These metals produce isomorphic substitutions that increase the catalytic activity in oxidative processes involving organic molecules of commercial interest, such as phenols, bulky aromatics, and terpineols (Kondam and Song, 1996).

This study will present results of synthesis and characterization of Aluminum and Titanium MCM-41 materials prepared in our laboratory using different surfactants and evaluated for the reaction of anthracene oxidation using different oxidants and solvents.

\section{EXPERIMENTAL SECTION}

\section{Materials}

All the reactants (alkoxides, solvents, oxidants, amine, alkylammonium salt, hydrocloric acid, ammonium hydroxide, anthracene and 9,10anthraquinone), of analysis grade ( $>98 \%$ ), were supplied by ACROS ORGANICS ${ }^{\circledR}$ with analytic purity degree (and used without any further purification.

\section{Methods}

\section{a) Synthesis}

The MCM-41 metal samples were prepared by the sol-gel method with the use of the alkoxides tetraethyl orthosilicate-TEOS (silicon), aluminum triisopropoxide (aluminum), and titanium tetraisopropoxide (titanium), and the surfactant agents dodecylamine (DA), dodecylamine hydrocloride (DAC1), and cetiltrimethyammonium chloride (CTACl). The typical procedure involves addition of alkoxides of $\mathrm{Ti}$ or $\mathrm{Al}$ to the TEOS in a Teflon flask, followed by dilution of the mixture with ethanol. For the initial mixture of
$\mathrm{Si}+\mathrm{Al}$ alkoxides, a water solution of cetiltrimethylammonium chloride was added. For the Ti-MCM-41 samples, either an alcohol solution of dodecylamine or an acid water solution $(\mathrm{pH}=1)$ of dodecylamine (salt preparation in situ) was added. The molar composition of the synthesis gel was 1 TEOS : 0.033 alkoxide (Ti or Al): 0.30 Surfactant: 5.2 Ethanol: $23 \mathrm{H}_{2} \mathrm{O}$. The reaction was initially conducted at pH 2.0 (alkoxide hydrolysis) for about $90 \mathrm{~min}$ under moderate agitation. At the end of the operation, the $\mathrm{pH}$ of the solution was adjusted to 10 with $30 \%$ ammonium hydroxide. The time of agitation varied between 75 and $90 \mathrm{~min}$. Once the alkaline phase had ended, the material was left still for $20 \mathrm{~h}$ at room temperature. Later the following phases were carried out: filtration in vacuum, washing with deionized water, drying $\left(6 \mathrm{~h}\right.$ at $\left.105^{\circ} \mathrm{C}\right)$, and calcination $(550$ $600^{\circ} \mathrm{C}$ in air atmosphere). The synthesized samples were named Al-CTACl, Ti-DA, and Ti-DACl.

\section{b) Characterization}

The samples were characterized by four analytical techniques as follows: X-Ray diffraction (DRX) in a Philips X'PertPro diffractometer using $\mathrm{CuK} \alpha$ radiation $(40 \mathrm{KV}$ and $40 \mathrm{~mA})$; infrared spectroscopy (FTIR) in a Bio-Rad spectrophotometer, using the attenuated total reflection technique (ATR); thermogravimetric analysis (TG/DTG) in a Shimadzu $5 \mathrm{OH}$ system with a platinum crucible, a synthetic air atmosphere, a $50 \mathrm{cc} / \mathrm{min}$ flow; and specific surface area $\left(\mathrm{A}_{\mathrm{BET}}\right)$ in a QuantaChrome Nova 2000 system. The same equipment was used to calculate the pore distribution by the BJH method.

\section{c) Catalytic Tests and Product Analysis}

Anthracene oxidation was used as a model reaction (see Figure 1) to assess the catalytic activity of the synthesized mesoporous materials. Batch catalytic tests were carried out in a bottom flask under magnetic agitation with anthracene dissolved in a solvent (either benzene- $\mathrm{C}_{6} \mathrm{H}_{6}$ or tetrahydrofuran-THF), followed by addition of the catalyst and the oxidant (either $\mathrm{H}_{2} \mathrm{O}_{2} 30 \%$ or tert-butyl hydroperoxide-TBHP $70 \%$ ). The reaction mixture was then left under reflux, while the change in the typical brown color of the quinones was observed. The reaction conditions used were as follows: catalyst/anthracene mass ratio of $1: 1$; solvent volume of $10 \mathrm{~mL}$; molar ratio anthracene/oxidant of 1:10; and time of reaction of 20h (Srinivas et al., 2002). The reaction was followed by high performance liquid chromatography using a Varian ProStar 150 model with a isocratic mode of $1 \mathrm{~mL} / \mathrm{min}$ flow of a mixture $\mathrm{CH}_{3} \mathrm{CN}-\mathrm{H}_{2} \mathrm{O} 80: 20, \lambda=$ $254 \mathrm{~nm}$. 


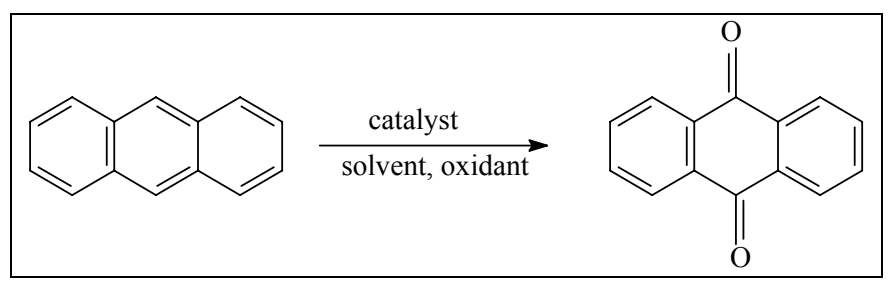

Figure 1: Model reaction used in the catalytic tests (anthracene $\rightarrow 9,10$-anthraquinone)

\section{RESULTS AND DISCUSSION}

\section{Synthesis of Mesoporous Materials in Different Surfactant Media}

The main characteristic of catalyst preparation by the sol-gel method is the presence of an acid phase that keeps the $\mathrm{Al}^{+3}$ and $\mathrm{Ti}^{+4}$ ions in solution. For the titanium catalysts this is a compulsory phase, since carrying out the process (hydrolysis and condensation) in a purely alkaline medium would produce the direct precipitation of titanium oxide, or $\mathrm{TiO}_{2}$, from the alkoxide (Luo et al., 2002). The types of gel initially elaborated were viscous suspensions that were easy to filtrate. After removal of the surfactants through calcination at $600^{\circ} \mathrm{C}$, an extremely thin white powder was obtained. All samples were prepared using $\mathrm{Si} /$ metal molar ratios of approximately $30: 1$ in the synthesis gel.

\section{Characterisation by XRD, BET, TG/DTG, FTIR}

\section{a) X-Ray Diffraction}

The diffraction profiles of the three synthesized samples are presented in Figure 2. It is possible to observe a peak for $2 \theta$ between $2^{\circ}$ and $3^{\circ}$, which is characteristic of the Bragg plane reflection (100). This is sufficient evidence of the presence of the MCM-41 structure (Blasco et al., 1995). There are no (110), (200), and (210) Bragg planes, which demonstrates poor ordering of the pore structure of our synthesized samples.

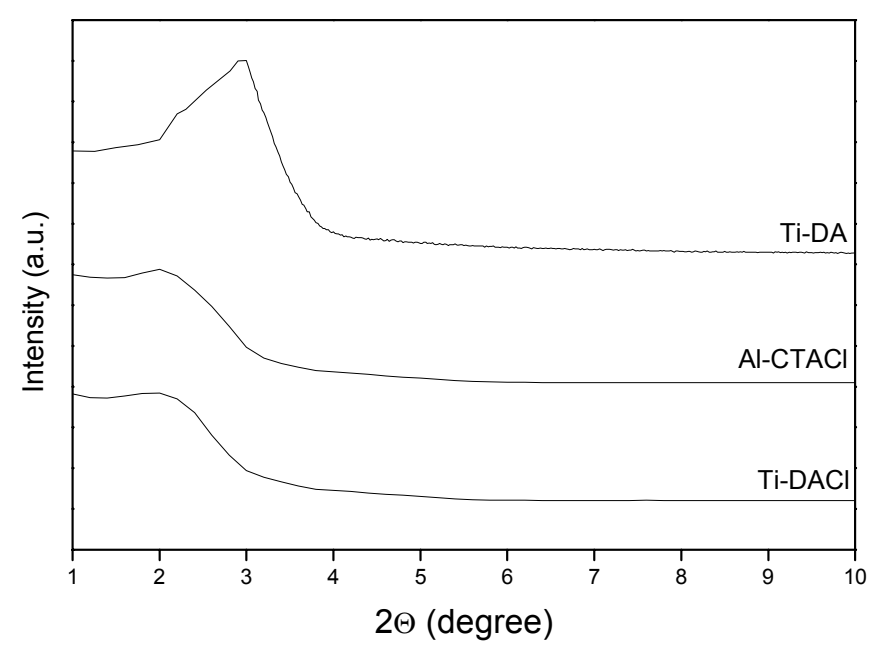

Figure 2: X-Ray profiles of the calcined samples.

\section{b) $\mathbf{N}_{2}$ Adsorption}

Surface areas $\left(\mathrm{A}_{\mathrm{BET}}\right)$ were determined from $\mathrm{N}_{2}$ adsorption at $77 \mathrm{~K}$ in a BET plot linear band $\left(\mathrm{P} / \mathrm{P}_{0}\right.$ $=0.05-0.30)$. The isotherms obtained were of type IV, in accordance with the IUPAC classification for mesoporous materials (Sing, 1998). The physical properties of the synthesized samples are listed in Table 1. The values for surface areas and pore diameters confirm the mesoporous nature of the synthesized materials, despite lower than usual values observed for the surface areas that were measured. This can be related to the lower crystallinity that was observed in the X-ray diffraction analysis indicative of the poor ordering of the pore structure of our samples. The pore diameters (between 2.8 and $3.2 \mathrm{~nm}$ ) are in the range usually observed for MCM-41 samples (Corma et al., 1994; Chen et al., 1999; Aguado et al., 2000). 
Table 1: Properties of calcined Al-MCM-41 and Ti-MCM-41 samples.

\begin{tabular}{|l|c|c|c|}
\hline \multirow{2}{*}{ Properties } & \multicolumn{2}{|c|}{ Samples } \\
\cline { 2 - 4 } & Ti-DA & Ti-DACl & Al-CTACI \\
\hline $\mathrm{d}_{100}(\AA)$ & 37.5 & 36.2 & 33.1 \\
$\mathrm{a}_{0}{ }^{*}(\AA)$ & 43.3 & 41.8 & 38.3 \\
$\mathrm{~A}_{\mathrm{BET}}\left(\mathrm{m}^{2} / \mathrm{g}\right)$ & 726 & 657 & 595 \\
Pore diameter $(\AA)$ & 28.1 & 31.1 & 32.0 \\
\hline
\end{tabular}

$* \mathrm{a}_{0}=2 \mathrm{~d}_{100} / 3^{1 / 2}$ (unit hexagonal cell parameter)

\section{c) Thermal Analysis (TG/DTG)}

The thermogravimetric curves (TG) and the respective differential curves (DTG) are shown in Figure 3. In all samples, thermal degradation peaks are observed, between 150 and $370^{\circ} \mathrm{C}$, corresponding to the removal of the surfactant. It may also be observed that moderate losses are noted between 550 and $600^{\circ} \mathrm{C}$, which may be attributed to dehydration and condensation of silanol groups at the surface of the samples (Cesteros et al., 2001).

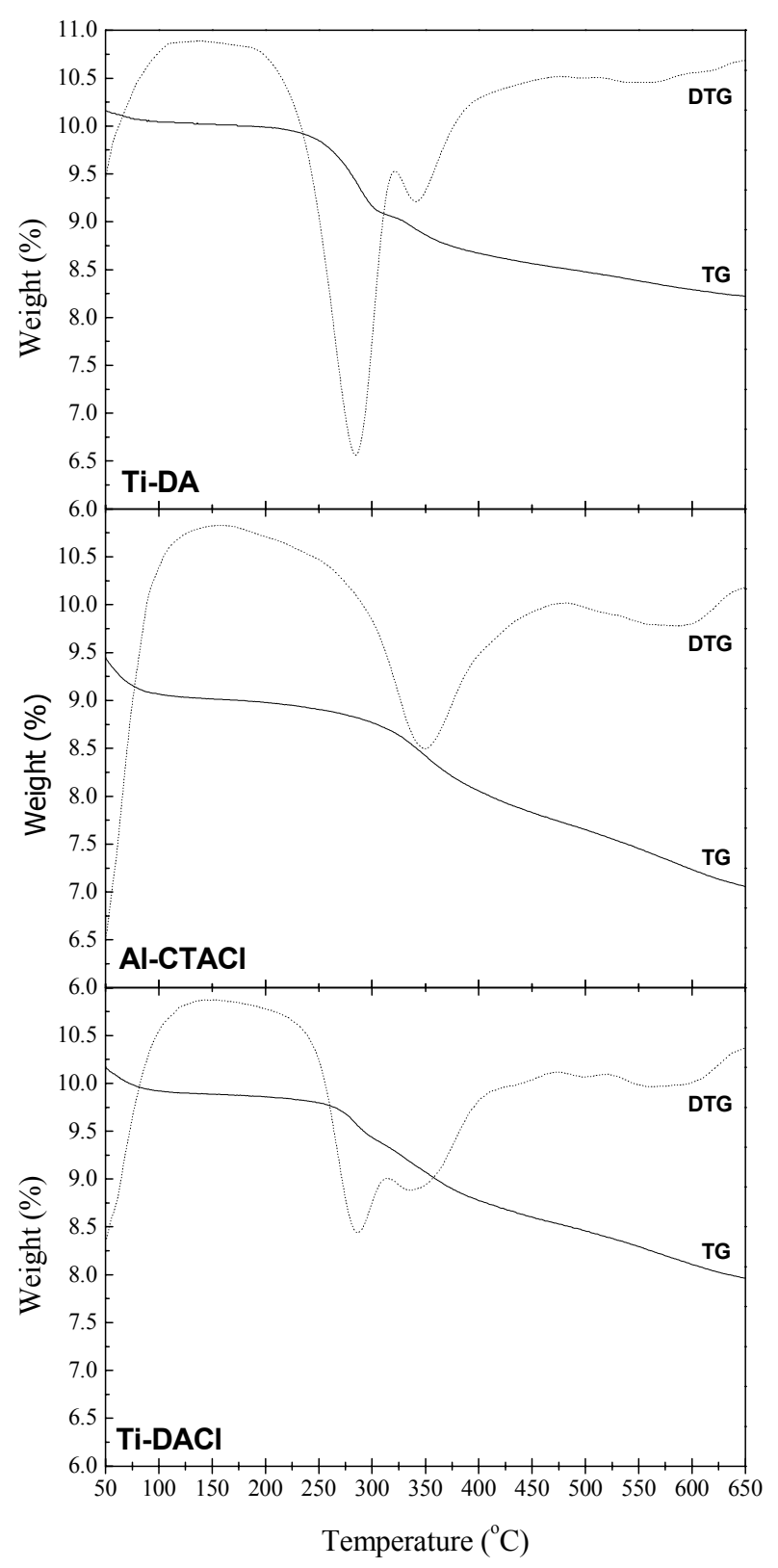

Figure 3: TG/DTG analyses of the dry samples. 


\section{d) IR Spectroscopy (FTIR)}

The infrared spectra of the synthesized samples are shown in Figure 4. Special attention should be paid to a few points. First, the presence of an intense band between 4000 and $3000 \mathrm{~cm}^{-1}$ in all samples which corresponds to the internal and external hydroxyl groups of the mesoporous structure. Second, a band between 1050 and 1250 $\mathrm{cm}^{-1}$ which is associated to asymmetrical tensions of $\mathrm{Si}-\mathrm{O}-\mathrm{Si}$ in the framework structures. Finally, the presence of a weak band situated between 960 and $970 \mathrm{~cm}^{-1}$, which is associated with the Si-O-R stretching, where $\mathrm{R}=\mathrm{H}^{+}, \mathrm{Ti}^{+4}$, or $\mathrm{Al}^{+3}$. The intensity of this band may be related to the amount of metals ( $\mathrm{Ti}$ or $\mathrm{Al})$ incorporated to the framework structure (Zholobenko et al., 1997; Chen et al., 1997).

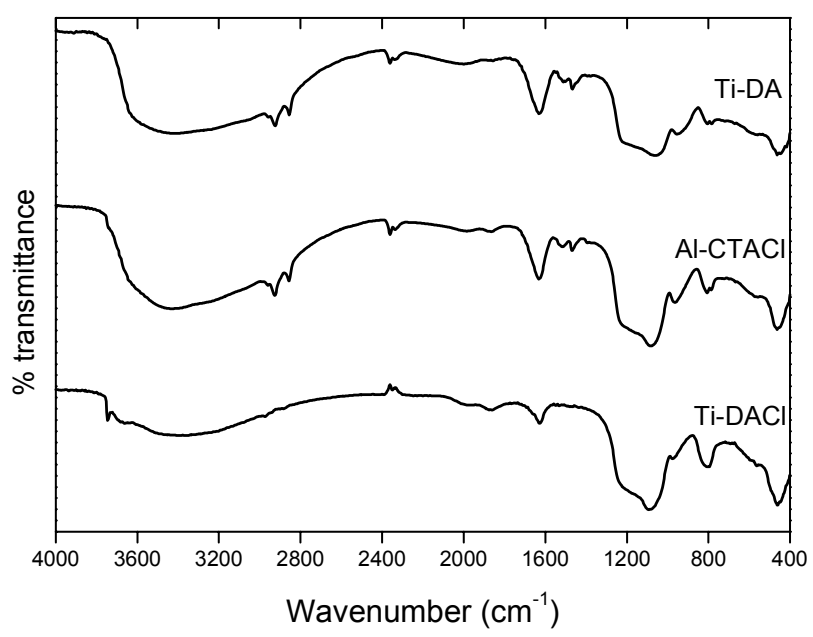

Figure 4: Infrared spectra of the Ti-DA sample after calcination

\section{Catalytic Results}

We performed comparative oxidation reaction tests using the samples we synthesized at the same reaction conditions as reported by Srinivas et al. (2002). We also carried out the reaction at the same conditions in the absence of a catalyst (with insignificant conversion to 9,10-anthraquinone), and using a commercial $\mathrm{Y}$ microporous zeolite $(\mathrm{Si} / \mathrm{Al}=1.6)$, to compare with our samples. All results of conversion and selectivity are listed in Table 2. It may be observed that all mesoporous samples have better selectivity and conversion than the $\mathrm{Y}$ microporous zeolite for this reaction. It may also be noted that the sample entitled Ti-DA (titanium MCM-41 prepared using dodecylamine as surfactant) yielded the higher values for conversion and selectivity $(71.2 \%$ and $98.8 \%$, respectively) of the three mesoporous samples, and was thus selected for the studies of oxidant and solvent effects that followed. For comparison, Srinivas et al. (2002) using a Ti-MCM-41 sample in a system with TBHP and benzene observed conversion and selectivity of $6.7 \%$ and $33.1 \%$, respectively.

To evaluate the effect of solvent and oxidant type on the anthracene oxidation reaction, we performed similar tests using benzene $\left(\mathrm{C}_{6} \mathrm{H}_{6}\right)$ and tetrahydrofurane (THF) as solvents, and hydrogen peroxide $\left(\mathrm{H}_{2} \mathrm{O}_{2}\right)$ and tert-butyl hydroperoxide (TBHP) as oxidants. Table 3 shows all the conversion and selectivity results. The best combination was for benzene as solvent and TBHP as oxidant, which yielded the best combined results of conversion and selectivity. It may be noted that for the benzene- $\mathrm{H}_{2} \mathrm{O}_{2}$ system, where the polarities of the species are too different, the conversion and selectivity to 9,10 anthraquinone proved to be insignificant.

Table 2: Effect of the type of catalyst on anthracene oxidation. Conditions: benzene $10 \mathrm{~mL}$, anthracene/TBHP 1:10 (molar), 0.1g catalyst, $0.1 \mathrm{~g}$ anthracene, reaction time $20 \mathrm{~h}$.

\begin{tabular}{|l|c|c|}
\hline Catalyst & Conversion (\%) & Selectivity (\%) \\
\hline Al-CTACl & 55.7 & 78.1 \\
Ti-DACl & 48.2 & 97.2 \\
Ti-DA & $\mathbf{7 1 . 2}$ & $\mathbf{9 8 . 8}$ \\
Y & 23.1 & 52.1 \\
no catalyst & 0.62 & 0.82 \\
\hline
\end{tabular}


Table 3: Effect of solvent and oxidant type on anthracene oxidation. Conditions: solvent $10 \mathrm{~mL}$, anthracene/oxidant 1:5 (molar), 0.1g Ti-DA, 0.1g anthracene, reaction time $20 \mathrm{~h}$.

\begin{tabular}{|c|c|c|}
\hline Solvent/Oxidant & Conversion (\%) & Selectivity (\%) \\
\hline $\mathrm{C}_{6} \mathrm{H}_{6} / \mathrm{H}_{2} \mathrm{O}_{2}$ & 8.2 & 3.3 \\
$\mathrm{THF} / \mathrm{H}_{2} \mathrm{O}_{2}$ & 72.1 & 44.3 \\
$\mathrm{C}_{6} \mathrm{H}_{6} / \mathrm{TBHP}$ & 71.2 & 98.8 \\
$\mathrm{THF} / \mathrm{TBHP}$ & 70.8 & 50.2 \\
\hline
\end{tabular}

\section{CONCLUSIONS}

Al-MCM-41 and Ti-MCM-41 samples were synthesized using the sol-gel method and different surfactants. The samples were characterized by infrared spectroscopy, $\mathrm{N}_{2}$ adsorption, X-ray diffraction, and thermal analysis. The samples were also tested for a previously reported oxidation reaction of anthracene to 9,10-anthraquinone (Srinivas et al., 2002) and evaluated with regards to solvent and oxidant effect. Our results indicate much better conversions and selectivities for our mesoporous samples as compared to a microporous zeolite, which may be further studied to try to more deeply understand the effect of the metal exchange in the framework structure.

\section{ACKNOWLEDGEMENTS}

The authors would like to acknowledge the financial support received from $\mathrm{CNPq}$, FINEP, and FUNCAP. Determination of nitrogen adsorption isotherms at the laboratory of Prof. Dulce Melo (UFRN) is gratefully acknowledged. XRD analysis were kindly performed at the Department of Physics (UFC).

\section{NOMENCLATURE}

$\begin{array}{llr}\mathrm{a}_{\mathrm{o}} & \text { unit hexagonal parameter } & \AA \\ \mathrm{d}_{100} & \text { interplanar distance } & \AA \\ \mathrm{P} & \text { equilibrium pressure } & \mathrm{kPa} \\ \mathrm{P} / \mathrm{P}_{\mathrm{o}} & \text { equilibrium relative pressure } & (-) \\ \mathrm{A}_{\mathrm{BET}} & \text { specific surface área } & \mathrm{m}^{2} / \mathrm{g}\end{array}$

\section{REFERENCES}

Aguado, J., Serrano. D.P. and Escola, J.M., A sol-gel approach for the room temperature synthesis of Al-containing micelle-templated silica. Microporous and Mesoporous Materials, 34, 43, 2000.
Arnold, A. B. J., Niederer, P. M., Nießen, T. E. W. and Hölderich, W., The influence of synthesis parameters on the vanadium content and pore size of V-MCM-41 materials. Microporous and Mesoporous Materials, 28, 353, 1999.

Beck, J.S., Vartuli, J.C., Roth, W.J., Leonowicz, M.E., Kresge, C.T., Schmitt, K.D., Chu, C.T.-W., Olson, D.H., Sheppard, E.W., McCullen, S.B., Higgins, J.B. and Schlenker, J.L., A new family of mesoporous molecular sieves prepared with liquid crystal templates. J. Am. Chem. Soc., 114, 10834, 1992.

Biz, S. and Occelli, M.L., Synthesis and Characterization of Mesostructured Materials, Catal. Rev. Sci. Eng, Vol 40 (3), p.329-407, 1998.

Blasco, T., Corma, A, Navarro, M.T. and Pariente, J.P., Synthesis, Characterization, and Catalytic Activity of Ti-MCM-41 Structures, Journal of Catalysis, Vol 156, p.65-74, 1995.

Blasco, T., Corma, A., Navarro, M.T. and PérezPariente, J., Synthesis, characterization, and catalytic activity of Ti-MCM-41 structures. J. Catal., 156, 65, 1995.

Cassiers, K., Van der Voort, P. and Vansant, E.F., Synthesis of stable and directly usable hexagonal mesoporous silica by efficient amine extraction in acidified water. Chem. Commun., 2489, 2000.

Cesteros, Y. and Haller, G. L., Several factors affecting Al-MCM-41 synthesis. Microporous and Mesoporous Materials, 43, 171, 2001.

Chen, L. Y., Ping, Z., Chuah, G. K., Jaenicke, S. and Simon, G., A comparison of post-synthesis alumination and sol-gel synthesis of MCM-41 with high framework aluminum content. Microporous and Mesoporous Materials, 27, 231, 1999.

Chen, L., Jaenicke, S. and Chuah, G. K., Thermal and hydrothermal stability of framework substitued MCM-41 mesoporous materials. Microporous Materials, 12, 323, 1997.

Corma, A., Fornés, V., Navarro, M.T. and PérezPariente, J., Acidity and stability of MCM-41 crystalline aluminosilicates. J. Catal., 148, 569, 
1994.

Corma, A., Navarro, M.T. and Pérez-Pariente, J., Synthesis of an ultra-large pore titanium silicate isomorphous to MCM-41 and its application as a catalyst for selective oxidation of hydrocarbons. J. Chem. Soc. Chem. Commun., 147, 1994.

Kondam., M.R. and Song, C., Synthesis of Mesoporous Zeolite and the Application for Catalytic Conversion of Polycylic Aromatic Hydrocarbons, Catalysis Today, Vol 31, p.137144, 1996.

Kresge, C.T., Leonowicz. W.J., Roth, J.C., Vartulli, J.C. and Beck, J.S., Ordered mesoporous molecular sieves synthesized by a liquid crystal template mechanism. Nature, 359, 710, 1992.

Luo, Y., Lu, G.Z., Guo, Y.L. and Wang, Y.S., Study on Ti-MCM-41 Zeolites Prepared with Inorganic Ti Sources: Synthesis, Characterization and Catalysis, Catalysis Communications, Vol 3, p.129-134, 2002.

Reddy, K. M. and Song, C., Synthesis of mesoporous zeolites and their application for catalytic conversion of polycyclic aromatic hydrocarbons. Catalysis Today, 31, 137, 1996.

Rodríguez-Castellón, E., Jiménez-López, A., Maireles-Torres, P., Jones, D.J, Rozière, J., Trombetta, M., Busca, G., Lenarda, M. and Storaro, L., Textural and structural properties and surface acidity characterizations of mesoporous silica-zirconia molecular sieves. J. Solid State. Chem., 175, 159, 2003.

Ryoo, R. and Kim, J.M., Structural order in MCM41 controlled by shifting silicate polymerization equilibrium. J. Chem. Soc., Chem. Commun., 711, 1995.

Sayari, A., Periodic Mesoporous Materials: Synthesis, Characterization and Potential Applications, Recent Advances and New Horizons in Zeolite Science and Technology, Studies in Surface Science and Catalysis, Vol 102, p.1-46, 1996.

Selvam, P., Badamali, S. and Sakthivel, A., Influence of aluminium sources on the synthesis and catalytic activity of mesoporous Al-MCM-41 molecular sieves. Catalysis Today, 63, 291, 2000.

Sing, K.S.W., Adsorption Methods for the Characterization of Porous materials, Advances in Colloid and Interfaces Science, 76-77, p.3-11, 1998.

Srinivas, N., Rani, V.R., Kulkarni, S.J. and Raghavan, K.V., Liquid Phase Oxidation of Antrachene and Trans-Stilbenzene over Modified Mesoporous (MCM-41) Molecular Sieves, Journal of Molecular Catalysis A: Chemical, 179, p.221-231, 2002.

Tuel, A., Modification of mesoporous silicas by incorporation of heteroelements in the framework. Microporous and Mesoporous Materials, 27, 151, 1999.

Ulagappan, N. and Rao, C.N.R., Synthesis and characterization of the mesoporous chromium silicates, Cr-MCM-41. Chem. Commun., 1047, 1996.

Zholobenko, V.L., Holmes, S.M., Cundy, C.S. and Dwyer, J., Synthesis of MCM-41 materials: an in situ FTIR study. Microporous Materials, 11, 83, 1997. 